\title{
Anticorpos anti-Leptospira spp. em animais selvagens do zoológico municipal de Ribeirão Preto, Estado de São Paulo, Brasil
}

\author{
Anti-Leptospira spp. antibodies in wild animals from Ribeirão Preto city zoo in \\ São Paulo State, Brazil
}

\author{
Carolina dos Santos SILVA ${ }^{1}$; Raul José Silva GÍRIO ${ }^{1}$; Guilherme GUERRA NETO'; \\ Michelle BRICH ${ }^{1}$; Lucas Alves de Souza SANTANA ${ }^{1}$; Fábio Henrique AMÂNCIO ${ }^{2}$; \\ Julia Rassi MARIANI ${ }^{3}$; Pedro Meirelles Favaretto WESSORT ${ }^{4}$
}

\author{
${ }^{1}$ Departamento de Medicina Veterinária Preventiva e Reprodução Animal da Faculdade de Ciências Agrárias e Veterinária da \\ Universidade Estadual Paulista, Jaboticabal-SP \\ ${ }^{2}$ Instituto Mamíferos Aquáticos, Salvador-BA \\ ${ }^{3}$ Médica Veterinária Autônoma \\ ${ }^{4}$ Bosque Zoológico Municipal “Dr. Fábio de Sá Barreto", Ribeirão Preto-SP
}

\begin{abstract}
Resumo
A leptospirose acomete todos os animais domésticos, selvagens e os seres humanos. Alguns estudos sorológicos realizados têm demonstrado o envolvimento de espécies selvagens na epidemiologia da doença. Uma vez que populações cativas de animais selvagens são pouco estudadas, principalmente no Brasil, o presente estudo teve como objetivo a detecção de anticorpos anti-Leptospira spp. em animais selvagens de cativeiro e de vida livre do Zoológico Municipal de Ribeirão Preto, estado de São Paulo, Brasil. Durante o período de março a outubro de 2006 foram colhidas 403 amostras de sangue das quais 388 animais (110 répteis, 143 aves, 110 mamíferos e 25 peixes) e 15 amostras de funcionários do zoológico Dentre as 388 amostras de animais, 339 eram animais cativos e 49 eram animais de vida livre capturados pelo uso de armadilhas. Os soros sanguíneos foram analisados por meio da prova de Soroaglutinação Microscópica (SAM) utilizando-se antígenos de 22 sorovares de leptospiras patogênicas e dois sorovares de leptospiras não patogênicas. Foram reagentes para leptospirose $103(103 / 388=26,5 \%)$ amostras, sendo $92(92 / 339=27,1 \%)$ amostras de animais cativos e $11(11 / 49=22,4 \%)$ de animais de vida livre. As 15 amostras de soro humanas foram negativas. Os títulos sorológicos nas amostras reagentes variaram de 40 a 5.120 com predominância dos títulos 40 e 80 e os sorovares Patoc, Andamana, Canicola, Icterohaemorrhagiae e Panama foram os mais frequentes.
\end{abstract}

Palavras-chave: Leptospirose. Animais selvagens. Zoológico. Sorovares.

\begin{abstract}
Leptospirosis may affect all domestic and wild animals as well as human beings. Some serological studies have shown the involvement of wild species in the epidemiology of the disease. Once captive wild animals are not much studied, especially in Brazil, the present study aimed to detect anti- Leptospira spp. antibodies in animals from Ribeirão Preto city zoo, in São Paulo state, Brazil. Blood samples were collected from captive birds, fish, reptiles and mammals, sinanthropics and free-living animals and also from employees between March and October, 2006. Four hundred and three blood samples were obtained, 388 animals' samples (110 reptiles, 143 birds, 110 mammals and 25 fish) and 15 humans' The sera were analysed by Microscopic Agglutination Test using 22 serovars from pathological leptospiras and two from non-pathological serovars. Among the animal samples, 339 were from captive animals, and 49 from free-living ones, captured with traps inside the zoo. One hundred and three $(103 / 388=26.5 \%)$ samples reacted to leptospirosis, ninety-two $(92 / 339=27.1 \%)$ samples were from captive animals and eleven $(11 / 49=22.4 \%)$ from freeliving ones. All humans' samples were negative. Serological titles varied from 40 to 5.120, with predominance of titles between 40 and 80 and the most frequent serovars were Patoc, Andamana, Canicola, Icterohaemorrhagiae and Panama.
\end{abstract}

Keywords: Leptospirosis. Wild animals. Zoo. Serovars.

\section{Introdução}

A leptospirose é uma doença bacteriana que acomete todos os animais domésticos, selvagens e os seres humanos, manifestando ou não os sinais clínicos e sintomas decorrentes da infecção. Inúmeros ani-
Correspondência para:

Carolina dos Santos Silva

Rua Benedicta Rodrigues Domingos, 889 Bl.Nice ap 43, CEP 14095-050,

Lagoinha, Ribeirão Preto, SP

e-mail: carolsantosilva@hotmail.com

Recebido: 23/04/2009

Aprovado: 04/03/2010 
mais domésticos, bem como a maioria das espécies selvagens, podem se tornar portadora e contribuir para a disseminação do microrganismo na natureza.

Em muitos países, investigações sobre a presença de leptospiras nos animais selvagens têm sido demonstradas em roedores, edentatas, carnívoros e artiodáctilos, os quais podem atuar como fontes de infecção ${ }^{1,2}$.

No Brasil, são escassos os estudos epidemiológicos nos animais selvagens ${ }^{3}$, porém atualmente alguns levantamentos sorológicos têm sido realizados em zoológicos e criadouros a fim de se obter mais dados sobre a leptospirose em populações cativas. Esses animais são especialmente expostos aos mais variados desequilíbrios dos fatores do meio ambiente onde vivem, pois convivem com a proximidade de muitas espécies selvagens diferentes, assim como espécies domésticas e sinantrópicas (gatos domésticos, pombos, roedores, insetos).

No Zoológico de Uberaba, Minas Gerais ${ }^{4}$ o exame de soroaglutinação microscópica (SAM) em animais de cativeiro incluindo aves, répteis, mamíferos e peixes, além de gatos domésticos errantes e roedores sinantrópicos, detectou $17(10,2 \%)$ animais reagentes apresentando título maior ou igual a 100, e os sorovares predominantes foram Canicola, Icterohaemorrhagiae, Andamana, Grippotyphosa e Patoc.

Em exames sorológicos realizados em 309 animais selvagens atendidos na Divisão de Veterinária da Fundação Parque Zoológico de São Paulo 5 , 290 animais mantidos em cativeiro e 12 animais sinantrópicos, foram encontrados 59 (19,5\%) animais sororreagentes. Diversas famílias de mamíferos foram estudadas e os sorovares mais encontrados foram Copenhageni, Pomona e Castellonis.

No Zoológico do Rio de Janeiro ${ }^{6}$, foram analisadas amostras de soro de 77 animais de 38 espécies diferentes de mamíferos e 51 (66,2\%) amostras foram reagentes, sendo que $29(37,7 \%)$ obtiveram título maior ou igual a 200, $15(19,5 \%)$ com título 100 e sete $(9,1 \%)$ demonstraram título 50 . Os sorovares encontrados foram Copenhageni, Icterohaemorrhagiae e Pomona.

No zoológico de Chapultepec na Cidade do Méxi$\mathrm{co}^{7} \mathrm{o}$ estudo apontou a ocorrência de Leptospira spp. em 48 amostras de soro de 19 espécies de mamíferos detectando 25 (52\%) delas positivas para um ou mais sorovares. Os sorovares encontrados foram Icterohaemorrhagiae, Canicola, Pyrogenes, Hebdomadis, Pomona, Grippotyphosa, Autumnalis e Panama.

O estudo sorológico para leptospirose em répteis, aves e peixes é de fundamental importância já que ainda não é conhecido o comportamento da doença nesses animais. Ainda não se sabe o tipo de resposta imunológica que eles desenvolvem nem se a padronização da SAM é correta, então as reações encontradas, mesmo com títulos baixos, são informações relevantes.

Portanto, pela escassez de informações sobre a leptospirose em animais selvagens e pela necessidade de se estudar o comportamento da doença em um ambiente de zoológico foi realizado um inquérito sorológico nos animais e funcionários do Bosque e Zoológico Municipal "Dr. Fábio de Sá Barreto” em Ribeirão Preto.

\section{Material e Método}

Foram analisadas 403 amostras de soro sanguíneo, colhidas no período de março a outubro de 2006, sendo 388 amostras de animais e 15 amostras humanas. Foram capturados e contidos 388 animais (110 répteis, 143 aves, 110 mamíferos e 25 peixes), dentre os quais 339 eram animais cativos e 49 eram animais de vida livre. As amostras humanas foram de 15 funcionários do zoológico entre tratadores, técnicos e estagiários.

A pesquisa de anticorpos contra Leptospira spp. nas amostras de soro foi realizada por meio da prova de Soroaglutinação Microscópica (SAM), utilizando-se uma coleção de antígenos composta de 22 sorovares de leptospiras patogênicas: Australis, Bratislava, Autumnalis, Butembo, Castellonis, Bataviae, Canicola, 
Whitcombi, Cynopteri, Grippotyphosa, Hebdomadis, Copenhageni, Icterohaemorrhagiae, Javanica, Panama, Pomona, Pyrogenes, Hardjo, Wolffi, Shermani, Tarassovi, Sentot e dois sorovares de leptospiras não patogênicas: Andamana e Patoc. Os soros considerados reagentes foram aqueles que apresentaram reação de aglutininas igual ou maior a $50 \%$ a partir da diluição $1 / 40$.

\section{Resultados}

Em 388 amostras de soro de animais analisadas, $103(26,5 \%)$ foram reagentes para leptospirose na SAM. Dos 339 soros de animais cativos testados, 92 $(27,1 \%)$ foram reagentes e dos 49 soros de animais de vida livre testados, $11(22,4 \%)$ foram reagentes para leptospirose. As 15 amostras de soro humanas foram negativas.
Considerando-se o total de 388 animais analisados, 103 foram reagentes na SAM, dos quais 47 (45,6\%) répteis, $34(33 \%)$ aves, $20(19,4 \%)$ mamíferos e dois $(2,0 \%)$ peixes.

Os sorovares predominantes nas amostras de animais cativos foram: Patoc $(27 / 92=29,3 \%)$, Andamana $(21 / 92=22,8 \%)$, Canicola $(10 / 92=10,8 \%)$, Icterohaemorrhagiae $(7 / 92=7,6 \%)$ e Panama $(7 / 92$ $=7,6 \%)$. Nas amostras de animais de vida livre, os sorovares encontrados foram Patoc $(5 / 11=45,4 \%)$, Autumnalis $(2 / 11=18,2 \%)$, Copenhageni $(2 / 11=$ $18,2 \%)$, Pyrogenes $(1 / 11=9,1 \%)$ e Australis $(1 / 11$ $=9,1 \%)$.

Os títulos sorológicos em todas as amostras reagentes variaram de 40 a 5.120 sendo que houve predominância dos títulos 40 e 80 e os sorovares Patoc e Andamana foram os mais frequentes (Tabela 1).

Tabela 1 - Frequência de aglutininas anti-Leptospira spp. em soro sanguíneo de 103 animais selvagens em cativeiro e de vida livre do zoológico de Ribeirão Preto, no período de março a outubro de 2006 - Brasil - 2009

\begin{tabular}{|c|c|c|c|c|c|c|c|c|c|c|}
\hline \multirow{2}{*}{ SOROVAR } & \multicolumn{9}{|c|}{ TÍTULO } & \multirow{2}{*}{ (\%) } \\
\hline & 40 & 80 & 160 & 320 & 640 & 1.280 & 2.560 & 5.120 & TOTAL & \\
\hline Patoc & 12 & 13 & 05 & 01 & 00 & 01 & 00 & 00 & 32 & 31,06 \\
\hline Andamana & 09 & 07 & 01 & 01 & 00 & 02 & 00 & 01 & 21 & 20,38 \\
\hline Canicola & 07 & 01 & 01 & 01 & 00 & 00 & 00 & 00 & 10 & 9,70 \\
\hline Icterohaemorrhagiae & 05 & 01 & 01 & 00 & 00 & 00 & 00 & 00 & 07 & 6,80 \\
\hline Panama & 02 & 02 & 00 & 00 & 00 & 00 & 03 & 00 & 07 & 6,80 \\
\hline Copenhageni & 01 & 01 & 02 & 00 & 01 & 01 & 00 & 00 & 06 & 5,82 \\
\hline Tarassovi & 00 & 02 & 02 & 01 & 00 & 00 & 00 & 00 & 05 & 4,85 \\
\hline Sentot & 02 & 00 & 00 & 00 & 01 & 00 & 00 & 00 & 03 & 2,91 \\
\hline Pomona & 00 & 00 & 00 & 00 & 00 & 02 & 00 & 00 & 02 & 1,94 \\
\hline Hebdomadis & 00 & 02 & 00 & 00 & 00 & 00 & 00 & 00 & 02 & 1,94 \\
\hline Autumnalis & 02 & 00 & 00 & 00 & 00 & 00 & 00 & 00 & 02 & 1,94 \\
\hline Pyrogenes & 01 & 01 & 00 & 00 & 00 & 00 & 00 & 00 & 02 & 1,94 \\
\hline Castellonis & 00 & 00 & 01 & 00 & 00 & 00 & 00 & 00 & 01 & 0,97 \\
\hline Butembo & 01 & 00 & 00 & 00 & 00 & 00 & 00 & 00 & 01 & 0,97 \\
\hline Australis & 01 & 00 & 00 & 00 & 00 & 00 & 00 & 00 & 01 & 0,97 \\
\hline Bratislava & 01 & 00 & 00 & 00 & 00 & 00 & 00 & 00 & 01 & 0,97 \\
\hline TOTAL & 44 & 30 & 13 & 04 & 02 & 06 & 03 & 01 & 103 & 100 \\
\hline
\end{tabular}




\section{Discussão}

No Bosque Zoológico Municipal “Dr. Fábio de Sá Barreto" de Ribeirão Preto as amostras de soro de animais cativos reagentes na SAM apresentaram sorovares predominantes semelhantes aos encontrados no Zoológico de Uberaba, Minas Gerais ${ }^{4}$, porém as frequências foram diferentes.

Os animais de vida livre reagentes em Ribeirão Preto foram um gavião carijó, um cachorro do mato, um pombo, três cutias, dois gambás e três ratos de telhado. Todos os répteis de vida livre e os gatos domésticos foram negativos na SAM. Na Fundação Parque Zoológico de São Paulo ${ }^{5}$ foram capturados cinco gambás e sete ratazanas e foram encontrados $42,8 \%$ e $40 \%$, respectivamente de sorologia positiva para o sorovar Icterohaemorrhagiae. No Zoológico de Uberaba, Minas Gerais ${ }^{4}$ foram capturados 27 ratos de telhado e foi detectado um animal positivo também para o sorovar Icterohaemorrhagiae.

Os dois gambás caracterizados como reagentes apresentaram aglutinação com o sorovar Patoc diferente de outros trabalhos realizados ${ }^{8,9,10,11}$ que encontraram reação com os sorovares Ballum, Bataviae, Icterohaemorrhagiae, Szwajizam, Grippotyphosa e Pomona nesse gênero animal. Os três ratos de telhado capturados foram reagentes para os sorovares Copenhageni, mesmo sorogrupo Icterohaemorrhagiae e Pyrogenes, semelhante a outros relatos ${ }^{4,5}$.

Os poucos estudos realizados com répteis apontaram estes animais como possíveis reservatórios da leptospirose ${ }^{12}$. No Zoológico de Ribeirão Preto, os répteis foram responsáveis por um grande número de amostras reagentes envolvendo os quelônios, sáurios e ofídeos.

As serpentes da família Boidae foram reagentes aos sorovares Canicola, Patoc, Andamana e Sentot discordando de relatos ${ }^{13}$ que demonstram reação positiva para os sorovares Andamana, Icterohaemorrhagiae, Ballum, Grippotyphosa e Pomona em soro de serpen- tes peçonhentas e não peçonhentas. No Zoológico de Uberaba $^{5}$, Minas Gerais, três amostras de soro sanguíneo de jibóias (Boa constrictor amarali) foram analisadas e negativas na SAM.

Os animais da Família Emydidae, tartarugas de orelha vermelha (Trachemys scripta elegans), foram reagentes (26/44) para os sorovares Andamana, Tarassovi e Canicola e em estudos sorológicos ${ }^{14,15} \mathrm{com}$ a mesma espécie, foram demonstrados os sorovares Ballum e Tarassovi como os mais prevalentes. A análise do soro sanguíneo de 20 exemplares de tartarugas de orelha vermelha demonstrou uma amostra positiva para o sorovar Patoc ${ }^{4}$.

Exemplares da Família Testudinidae, jabuti piranga (Geochelone carbonaria) e jabuti tinga (Geochelone denticulata) foram reagentes (08/29) para os sorovares Patoc, Hebdomadis e Canicola. Há apenas um relato ${ }^{4}$ referindo uma amostra positiva para o sorovar Andamana em 16 animais desta família.

Entre os animais da Família Chelidae, cágado de barbicha (Phrynops geoffroanus) (01/02), Família Pelomedusidae, tartaruga da amazônia (Podocnemis expansa) (03/04) e tracajá (Podocnemis unifilis) (02/02), e da Família Gekkonidae, Iguana (Iguana iguana) (01/04) foram reagentes e não foram encontrados na literatura relatos de sorologia positiva para leptospirose nesses animais.

O grupo das aves representou 33\% dos animais reagentes no presente estudo e, apesar de ser pouco estudado, alguns autores já relataram sorologia positiva em galinhas ${ }^{16,17}$. Os soros sanguíneos de 48 aves do Zoológico de Uberaba, Minas Gerais ${ }^{4}$ foram analisados e todos foram negativos na SAM. Em Ribeirão Preto, foram reagentes 34 aves das Famílias Accipitridae, Anatidae, Anseranatidae, Columbinae, Cracidae, Phasianidae, Psittacidae e Ramphastidae e os sorovares mais frequentes foram Patoc, Copenhageni e Panama.

No Zoológico de Ribeirão Preto das 25 amostras de soro sanguíneo de peixes, duas foram reagentes para 
os sorovares Icterohaemorrhagiae e Bratislava. Em Uberaba, sete amostras de soro sanguíneo de peixes foram estudadas e seis $(85,75 \%)$ delas foram positivas para o sorovar Canicola ${ }^{4}$.

Os títulos sorológicos encontrados em todas as amostras reagentes do Zoológico de Ribeirão Preto variaram de 40 a 5.120 com predominância de títulos baixos como 40 e 80 , o que demonstra a baixa intensidade de infecção, mas grande circulação do agente, já que esses resultados apontam que os animais entraram em contato com as leptospiras.

Nesta pesquisa, houve a ocorrência de títulos altos em exemplares de aves e répteis indicando infecção ativa, podendo ou não, apresentar manifestação clínica da doença e, consequentemente, eliminação de leptospiras na urina. Porém, não se sabe como as leptospiras desenvolvem seu ciclo nesses animais, ressaltando assim, o alerta para a necessidade de pesquisar a doença em aves e répteis.

\section{Referências}

1.MICHNA, S. W.; CAMPBEL, R. S. F. Leptospirosis in wild animals. Journal of Comparative Pathology, v. 38, n. 7, p. 440-442, 1997.

2.REILLY, J. R.; FERRIS, D. H.; HANSON, L. E. Experimental demonstration of the enteric route of infeccion with Leptospira Grippotyphosa in wild carnivores. American Journal of Veterinary Research, v. 29, n. 9, p. 1849-1854, 1968.

3.GIRIO, R. J. S.; HERRERA, R. C. P.; PEREIRA, F. J. G.; MATHIAS, L. A. Pesquisa de infecção por Leptospira interrogans em animais da região de Nhecolândia, no Pantanal do Mato Grosso do Sul. Arquivo Instituto Biológico, v. 65, p. 87, 1999. Suplemento.

4.ESTEVES, F. M.; GUERRA-NETO, G.; GIRIO, R. J. S.; SILVAVERGARA, M. L.; CARVALHO, A. C. F. B. Detecção de anticorpos para Leptospira spp em animais e funcionários do Zoológico Municipal de Uberaba, MG. Arquivo Instituto Biológico, v. 72, n. 3, p. 283-288, 2005.

5.CORRÊA, S. H. R.; VASCONCELLOS, S. A.; MORAIS, Z.; TEIXIERA, A. A.; DIAS, R. A.; GUIMARÃES, M. A. B. V. FERREIRA, F.; FERREIRA-NETO, J. S. Epidemiologia da Leptospirose em animais silvestres na Fundação Parque Zoológico de São Paulo. Brazilian Journal of Veterinary Research and Animal Science, v. 41, n. 3, p. 189-193, 2004.

6.LILENBAUM, W.; MONTEIRO, R. V.; RISTOW, P.; FRÁGUAS, S.; CARDOSO, V. S.; FEDULLO, L. P. L. Leptospirosis antibodies in mammals from Rio de Janeiro Zôo, Brazil. Research in Veterinary Science, v. 73, n. 3, p. 319-321, 2002.

\section{Conclusões}

A Leptospira spp. estava presente no zoológico acometendo tanto animais cativos quanto animais de vida livre, apresentando maior frequência dos sorovares não patogênicos, Patoc e Andamana.

As amostras de soro sanguíneo de répteis, aves e peixes foram reagentes para diversos sorovares de Leptospira spp. demonstrando a susceptibilidade desses grupos ao agente e apontando a necessidade de novos estudos com esses animais.

\section{Agradecimentos}

Agradecemos aos amigos, funcionários, técnicos e estagiários do Bosque Zoológico de Ribeirão Preto por toda a ajuda e por permitirem a realização dos trabalhos. Ao técnico do Laboratório de Leptospirose, Nivaldo Aparecido de Assis, por todos os ensinamentos, pela atenção e ajuda essenciais ao desenvolvimento de todo o trabalho.

7.LUNA-ALVARES, M. A; MOLES-CERVANTES, L. P.; TORRES-BARRANCA, J. I.; GUALL-SILL, F. Investigación serologica de leptospirosis en fauna silvestre mantenida en cautiverio en el zoológico de Chapultepec de la Ciudad de México. Veterinaria México, v. 27, n. 3, p. 229-234, 1996.

8.CALDAS, E. M.; FEHRINGER, W. T; SAMPAIO, M. B. Aglutininas anti-leptospiras em Rattus norvegicus e Didelphis marsupialis em Salvador, Bahia. Arquivos da Escola de Medicina Veterinária da Universidade da Bahia, Salvador, v. 15, n. 1, p. 43-50, 1992.

9.CORDEIRO, F; SULZER, C. R.; RAMOS, A. A. Leptospira interrogans in several wildlife species in Southeast Brazil. Pesquisa Veterinária Brasileira, Rio de Janeiro, v. 1, n. 1, p. 19-29, 1981.

10.HATHAWAY, S. C.; BLACKMORE, D. K.; MARSHALL, R. B. Leptospirosis in free living species in New Zeland. Journal of Wildlife Diseases, Kansas, v. 7, n. 4, p. 489-496, 1981.

11.SANTA ROSA, C. A.; SULZER, C. R.; GIORGI, W.; SILVA, A. S.; YANAGUITA, R. M.; LOBAO, A. O. Laptospirosis in wildlife in Brazil: isolation of a new serotype in the pyrogenes group. American Journal of Veterinary Research, v. 36, n. 9, p. 1363-1365, 1975.

12. OLIVEIRA, P. M. A. Animais silvestres e exóticos na clínica particular. São Paulo: Roca, 2003.

13.SANTA ROSA, C. A.; SULZER, C. R.; YANAGUITA, R. M.; SILVA, A. S. Leptospirosis in wildlife in Brazil; isolation of serovars: canicola, pyrogenes and grippotyphosa. International Journal of Zoonosis, v. 7, p. 40-43, 1980. 
14. ANDREWS, R. D.; REILLY, J. R.; FERRIS, D. H.; HANSON, L. E. Leptospiral agglutinins in sera from southern Illinois herpetofauna. Journal of Wildlife Diseases, Kansas, v. 1, n. 4, p. 55-59, 1965.

15. GLOSSER, J. W.; SULZER, C. R.; EBERHARDT, M.; WINKLER, W. G. Cultural and serologic evidence of Leptospira interrogans serotype Tarassovi infection in turtles. Journal of Wildlife Diseases, Kansas, v. 10, p. 429-435, 1974.
16.CAFFARENA, R.; TRENCHI, H.; MENDEZ-ALGORTA, R.; TRENCHI, R.; SANDE, S. Serological data on leptospira in fowls. Veterinaria Argentina, Buenos Aires, v. 6, n. 51, p. 4045, 1989 .

17.EVERARD, C. O. R.; FRASER-CHANPONG, G. M.; BHAGWANDIN, L. J.; RACE, M. W.; JAMES, A. C. Leptospirosis in wildlife from Trinidad and Grenada. Journal of Wildlife Diseases, Kansas, v. 19, n. 3, p. 192-199, 1983. 